\title{
Efficiency of DRL responding as a function of response effort*
}

\author{
JEFF S. TOPPING, JOHN W. PICKERING, and JERRY A. JACKSON† \\ Mississippi State University, State College, Miss. 39762
}

The present study examined the relationship between DRL efficiency and response effort. One group of pigeons was required to emit a keypeck of at least $45 \mathrm{~g}$ force to operate the response $\mathrm{key}$, while a second group had to respond with a minimum force of $15 \mathrm{~g}$. Results indicated that the $45 \mathrm{~g} \mathrm{~g}$ Ss were significantly more efficient than the $15 \mathrm{~g} \mathrm{Ss}$, although this finding was not due to the former Ss' ability to inhibit responding.

Kramer \& Rilling's (1970) review of differential reinforcement of low rate (DRL) schedules indicates that the performance of pigeons on this schedule is markedly inferior to that of other species. In terms of the percentage of reinforced responses, i.e., efficiency ratios, Kramer \& Rilling (1969) found that pigeons were approximately $2 \%$ efficient on a DRL 20 -sec schedule. Similarly, Holz \& Azrin (1963), Holz, Azrin, \& Ulrich (1963), and Staddon (1965) have observed less than $2 \%$ efficiency on DRL 30-sec schedules.

Recently Hemmes (1970) has concluded that the pigeon's inefficiency on DRL schedules is dependent on the nature of the operant response. Noting that all previous studies with pigeons had employed the keypecking response, Hemmes used a treadle response and witnessed between $20 \%$ and $25 \%$ efficiency on DRL 20 -sec schedules.

Utilizing Hemmes's (1970) conclusion, the present experiment was designed to further investigate nontemporal determinants of DRL performance in pigeons. It was noted that all previous work on keypecking had used situations in which Ss had to respond with a minimum of $12-16 \mathrm{~g}$ force to operate the key. It was hypothesized that requiring $\mathrm{Ss}$ to respond with a much greater force to operate the key would result in greater efficiency since Ss would probably be less likely to emit effective responses. SUBJECTS

Six experimentally naive male White King pigeons, individually housed, served as Ss and were maintained at approximately $75 \%$ of their free-feeding weights for a period extending from 1 week prior to the experiment through the duration of the experiment.

* Supported in part by National Science Foundation Institutional Grant for Science R 200J-4450.

tRequests for reprints should be sent to Jeff S. Topping, P.O. Drawer PF. Mississippi State University, State College, Miss. 39762.

\section{APPARATUS}

A standard three-key pigeon chamber, $19 \frac{1 / 2}{2} 14 \times 14$ in., was located within a sound-attenuating ventilated cubicle. The 1 -in.-diam keys were centered, $10 \mathrm{in}$. from the floor and 4 in. apart, on a metal panel separating the S's chamber from the area containing the stimulus- and food-presenting mechanisms. Only the center key was employed in the present experiment, and the other keys were covered by metal plates. A minimum force of either 15 or $45 \mathrm{~g}$ was required to operate the key, and responses produced auditory feedback. $A$ one-plane readout allowed white light to be projected on the response key, and the experimental chamber was diffusely lighted from above by two small lightbulbs. Three inches from the bottom of the intelligence panel was centered a $2 \times 2$ in. opening, through which a solenoid-operated grain hopper could be presented. Reinforcement consisted of a 5 -sec access to the illuminated grain hopper. A white-noise generator functioned throughout the experiment to mask extraneous noises and a blower regulated the temperature inside the chamber. A system of automatic controlling and recording equipment allowed the data to be collected in a separate room.

\section{PROCEDURE}

Following reduction to their respective $75 \%$ weights, Ss received 2 days of magazine training, during which 40 reinforcements were given daily according to a noncontingent variable-interval (VI) 20 -sec schedule. On the next 3 days Ss were shaped (CRF) to peck the response key and allowed to make 40 continuously reinforced responses daily. To operate the key, half of the Ss (Group 15) were required to emit a response of at least $15 \mathrm{~g}$ force, while the remaining $\mathrm{Ss}$ (Group 45) had to give a response of at least $45 \mathrm{~g}$ force. These conditions held throughout the experiment. Ss were than switched to a DRL 4-sec schedule, and the DRL value was increased daily in 1-sec steps until a
DRL 20-sec schedule was obtained. All sessions with the DRL schedules were terminated after 40 reinforcements or $90 \mathrm{~min}$, whichever occurred first. All Ss received a total of 30 daily sessions on the DRL 20-sec schedule.

RESULTS AND DISCUSSION

The mean response rate and percentage of reinforced responses during the final 4 days on the DRL 20 -sec schedule are presented for each $\mathrm{S}$ in Table 1.

A $t$ test was performed on the percentage of reinforced responses data of Table 1 in order to compare the two groups. Results of this analysis yielded a significant difference $(\mathrm{t}=10.96, \mathrm{df}=4, \mathrm{p}<.01)$, indicating that Group 45 was more efficient in responding than Group 15. An additional $t$ test was conducted on the response rate data and indicated that Group 45 was responding at a significantly lower rate $(t=3.64$, $\mathrm{df}=4, \mathrm{p}<.05)$ than Group 15 .

It is also important to note that the percentages of reinforced responses for Ss in Group 15 were very much in agreement with findings from previous studies employing similar DRL conditions (Holz \& Azrin, 1963; Holz, Azrin, \& Ulrich, 1963; Kramer \& Rilling, 1969; Staddon, 1965).

The present results support Hemmes's (1970) conclusion that DRL performance is a function of the nature of the operant and emphasize the importance of nontemporal factors on spaced-responding schedules. Obviously, having to keypeck with at least a 45-g force is quite different from responding with a minimum force of $15 \mathrm{~g}$. Visual observation of Group 45 indicated that the superior performance of these Ss was not attributable to their ability to suppress keypecking during the required temporal intervals. Instead, these Ss typically hovered near the response key and emitted numerous noncriterion keypecks, i.e., pecks of less than $45 \mathrm{~g}$ force, or head movements in the direction of the key. These noncriterion responses and head movements functioned to mediate the 20 -sec interval in a fashion analogous to superstitious behavior. These mediating responses obviously provided less time for effective

Table 1

Terminal DRL Responding

\begin{tabular}{cccc}
\hline & S & $\begin{array}{c}\text { Response } \\
\text { R.ate }\end{array}$ & $\begin{array}{c}\text { Percentage of } \\
\text { Reinforced } \\
\text { Responses }\end{array}$ \\
\hline Group & 1 & $8.41 / \mathrm{min}$ & $\mathbf{0 . 9 2}$ \\
15 & 2 & 10.67 & 0.68 \\
& 3 & 10.92 & 1.03 \\
Group & 4 & 6.94 & 21.44 \\
45 & 5 & 7.33 & 16.72 \\
& 6 & 6.13 & 22.37 \\
\hline
\end{tabular}


keypecks and could explain the lowered response rates and subsequent more efficient DRL responding in Group 45.

REFERENCES

HEMMES, N. S. DRL efficiency depends upon the operant. Paper presented to the
Psychonomic Society, San Antonio, Texas, 1970.

HOLZ, W. C., \& AZRIN, N. H. A comparison of several procedures for eliminating behavior. Journal of the Experimental Analysis of Behavior, 1963 . 6, 399-406.

HOLZ, W. C.. AZRIN, N. H., \& ULRICH, R. E. Punishment of temporally spaced responding. Joumal of the Experimental Analysis of Behavior, $1963,6,281-290$. KRAMER, T. J., \& RILLING, M. Effects of timeout on spaced responding in pigeons. Journal of the Experimental Analysis of Behavior, 1969, 12, 283-288.

KR A MER 、 T. J., \& RILLING, M. Differential reinforcement of low rates: $A$ selective critique. Psychological Bulletin. $1970,74,225-254$.

STADDON, J. E. R. Some properties of spaced responding in pigeons. Journal of the Experimental Analysis of Behavior. $1965,8,19-28$

\section{CURRENT LITERATURE ON REINFORCEMENT IN ANIMALS}

ALVORD, J., CHENEY, C., \& DALEY, $\dot{M}$. (Upper Midwest Regoinal Education Laboratory, 1640 East 78th Street, Minneapolis, Minn. 55423). Development and control of licking in the guinea pig (Cavia porcellus). Behavior Research Methods \& Instrumentation, 1971, 3, 14-15.

BOE, E. E. (Graduate School of Education, University of Pennsylvania, Philadelphia, Penn. 19104 ). Variable punishment. Journal of Comparative and Physiological Psychology, 1971, 75, 73-76.

CAMPBELL, E. M., \& MEYER, P. A. (University of South Dakota, Vermillion, S. Dak. 57069). Effects of daily reward sequence on simultaneous and successive negative contrast in rats. Journal of Comparative and Physiological Psychology, 1971, 74, 434-440.

CAMPBELL, P. E. (Southern Methodist University, Dallas, Tex. 75222), CRUMBAUGH, C. M., RHODUS, D. M., \& KNOUSE, S. B. Magnitude of partial reward and amount of training in the rat: An hypothesis of sequential effects. Journal of Comparative and Physiological Psychology, 1971, 75, 120-128.

CAPALDI, E. J. (Purdue University, Lafayette, Ind. 47907), \& SPARLING, D. L. Amobarbital and the partial reinforcement effect in rats: Isolating frustrative control over instrumental responding.
Journal of Comparative and Physiological Psychology, 1971, 74, 467-477.

CARLISLE, H. J. (University of California, Santa Barbara, Calif. 93106). Fixed-ratio polydipsia: Thermal effects of drinking, pausing, and responding. Journal of Comparative and Physiological Psychology, 1971, 75, 10-22.

DAVIS, R. E. (Mental Health Research Institute, University of Michigan, Ann Arbor, Mich. 48104), \& KENYON, R. B. Registration of operant responses in fish. Behavior Research Methods \& Instrumentation, 1971, 3, 19-20.

HEARST, E. (Indiana University, Bloomington, Ind. 47401). Differential transfer of excitatory versus inhibitory pretraining to intradimensional discrimination learning in pigeons. Journal of Comparative and Physiological Psychology, 1971, 75, 206-215.

KELSEY, J. E., \& GROSSMAN, S. P. (University of Chicago, Chicago, $\mathrm{Ml}$. 60637 ). Non perseverative disruption of behavioral inhibition following septal lesions in rats. Journal of Comparative and Physiological Psychology, 1971, 75, 302-311.

KHAVARI, K. A. (University of Wisconsin-Milwaukee, Milwaukee, Wis. 53201). Adrenergic-cholinergic involvement in modulation of learned behavior. Journal of Comparative and Physiological Psychology, 1971, 74, 281-291.
KNOUSE, S. B., \& CAMPBELL, P. E. (Southern Methodist University, Dallas, Tex. 75222). Partially delayed reward in the rat: A parametric study of delay duration. Journal of Comparative and Physiological Psychology, 1971, 75, 116-119.

KRANE, R. V., \& ISON, J. R. (University of Rochester, Rochester, N.Y. 14627). Positive induction in differential instrumental conditioning: Effect of the interstimulus interval. Journal of Comparative and Physiological Psychology, 1971, 75, 129-135.

LEACH, D. A. (College of Wooster, Wooster, Ohio 44691). Rats' extinction performance as a function of deprivation level during training and partial reinforcement. Journal of Comparative and Physiological Psychology, 1971, 75, 317-323.

MATTHEWS, T. J. ( University College of Arts and Science, New York University, New York, N.Y. 10453). Thermal motivation in the rat. Journal of Comparative and Physiological Psychology, 1971, 74, 240-247.

POULOS, C. X., SHEAFOR, P. J., \& GORMEZANO, I. (University of Iowa, Iowa City, Iowa 52240). Classical appetitive conditioning of the rabbit's (Oryctolagus cuniculus) jaw-movement response with a single-alternation schedule. Journal of Comparative and Physiological Psychology, 1971, 75, 231-238. 